\title{
The Elusive Antifibrotic Macrophage
}

\author{
Adhyatmika Adhyatmika' ${ }^{1 \dagger}$, Kurnia S. S. Putri ${ }^{1,2,3 \dagger}$, Leonie Beljaars ${ }^{1}$ and Barbro N. Melgert ${ }^{1,4 \star}$ \\ 'Department of Pharmacokinetics, Toxicology and Targeting, Groningen Research Institute for Pharmacy (GRIP), University \\ of Groningen, Groningen, Netherlands, ${ }^{2}$ Department of Pharmaceutical Technology and Biopharmacy, Groningen Research \\ Institute for Pharmacy (GRIP), University of Groningen, Groningen, Netherlands, ${ }^{3}$ Faculty of Pharmacy, University of \\ Indonesia, Depok, Indonesia, ${ }^{4}$ GRIAC Research Institute, University Medical Center Groningen, University of Groningen, \\ Groningen, Netherlands
}

Fibrotic diseases, especially of the liver, the cardiovascular system, the kidneys, and the lungs, account for approximately $45 \%$ of deaths in Western societies. Fibrosis is a serious complication associated with aging and/or chronic inflammation or injury and cannot be treated effectively yet. It is characterized by excessive deposition of extracellular matrix (ECM) proteins by myofibroblasts and impaired degradation by macrophages. This ultimately destroys the normal structure of an organ, which leads to loss of function. Most efforts to develop drugs have focused on inhibiting ECM production by myofibroblasts and have not yielded many effective drugs yet. Another option is to stimulate the cells that are responsible for degradation and uptake of excess ECM,

OPEN ACCESS

Edited by:

Jean-Yves Scoazec,

Gustave Roussy Institute, France

Reviewed by:

Pier Paolo Piccaluga, University of Bologna, Italy

Kenji Notohara,

Kurashiki Central Hospital, Japan

*Correspondence:

Barbro N. Melgert

b.n.melgert@rug.nl

${ }^{\dagger}$ Adhyatmika Adhyatmika and Kurnia S. S. Putri have contributed equally to this work.

Specialty section: This article was submitted to Pathology, a section of the journal Frontiers in Medicine

Received: 28 July 2015

Accepted: 29 October 2015

Published: 13 November 2015

Citation:

Adhyatmika A, Putri KSS, Beljaars L and Melgert BN (2015) The Elusive Antifibrotic Macrophage.

Front. Med. 2:81.

doi: 10.3389/fmed.2015.00081 i.e., antifibrotic macrophages. However, macrophages are plastic cells that have many faces in fibrosis, including profibrotic behavior-stimulating ECM production. This can be dependent on their origin, as the different organs have tissue-resident macrophages with different origins and a various influx of incoming monocytes in steady-state conditions and during fibrosis. To be able to pharmacologically stimulate the right kind of behavior in fibrosis, a thorough characterization of antifibrotic macrophages is necessary, as well as an understanding of the signals they need to degrade ECM. In this review, we will summarize the current state of the art regarding the antifibrotic macrophage phenotype and the signals that stimulate its behavior.

Keywords: macrophages, antifibrotic, fibrosis, resolution, monocytes, MMP, cathepsin K, polarization

\section{INTRODUCTION}

Fibrosis is a serious complication associated with aging and with chronic injury and inflammation within an organ. It is characterized by progressive and irreversible destruction of normal architecture of an organ by excessive deposition of extracellular matrix (ECM). The excess ECM ultimately leads to organ malfunction and death because there are no effective therapies to stop or reverse fibrosis development. A mechanistic understanding of how ECM homeostasis is maintained in healthy situations, the similarities and differences between the various organs, and how it becomes dysregulated in fibrosis is of vital importance for defining novel targets for therapy. More insight into these processes will help the development of novel antifibrotic drugs.

Production of ECM is part of a normal repair response after tissue damage. Tissue repair has distinct stages, including a clotting phase, an inflammatory phase, a (myo)fibroblast proliferation phase, and a remodeling phase in which normal tissue architecture is restored (1). During the remodeling phase, myofibroblasts produce ECM and promote tissue contraction, which will ultimately 
lead to resolution of the damage. The current dogma is that ongoing microinjury within an organ induces an imbalance in ECM homeostasis and subsequently leads to fibrosis $(2,3)$. In most organs, ECM-producing myofibroblasts are found in close proximity with macrophages, and there is increasing evidence that suggests that normally these two cell types interact in many ways to control ECM homeostasis and that these interactions may be dysregulated in fibrosis (3-6). Myofibroblasts, as the major producers of ECM, have been the focus of fibrosis research for many years. Unfortunately, this has not yielded many successful drugs yet. Therefore, the role macrophages have in controlling ECM production in fibrosis has been getting more attention recently.

Macrophages are important cells in all stages of the fibrotic process (7). On the one hand, they have been found to promote fibrosis by secreting profibrotic mediators such as transforming growth factor beta (TGF $\beta$ ) and platelet-derived growth factor (PDGF) that induce proliferation and activation of myofibroblast (7-9). On the other hand, they also facilitate the resolution of fibrosis by producing specific matrix metalloproteinases (MMPs) and other proteolytic enzymes like cathepsins that degrade fibrotic ECM, and they express receptors that can phagocytose pieces of degraded ECM (10). Studies in models of pulmonary and liver fibrosis have shown that when macrophages are depleted during the early, inflammatory phase of fibrosis, ECM deposition was reduced but when they are depleted during the remodeling phase, ECM deposition was aggravated (8-11). These studies elegantly showed that the behavior of macrophages is highly plastic, but it remains unclear how the pro- and antifibrotic activities of macrophages are regulated. Knowing which signals induce antifibrotic behavior of macrophages is particularly important because restoration of normal tissue architecture can only proceed if the deposited excess ECM is removed. These signals may subsequently be used for the development of a whole new class of antifibrotic drugs. However, discerning antifibrotic macrophages from other macrophages is difficult, since characteristic markers are unclear, as are the signals that induce antifibrotic macrophages.

In this review, we will discuss evidence currently present in the literature that enables us to identify antifibrotic macrophages and the signals that are needed to induce them in order to design macrophage-directed antifibrotic therapeutics. Studies used for this review were gathered by a systematic search of Pubmed using the keywords "macrophages," "fibrosis," and "(resolution OR antifibrotic)." Only studies discussing pro- or antifibrotic activities of macrophages or phenotypical markers of these macrophages were included.

\section{MACROPHAGE PLASTICITY}

Macrophages have many roles in the immune system and are strongly involved in fighting microbial threats, inflammation, repair and resolution to return to homeostasis. For years, researchers have tried to define distinct macrophage polarization states or phenotypes that are responsible for these different tasks (12). They have been classified in several different ways, mostly into two main groups with M1 macrophages as the classically activated macrophages and M2 macrophages as the alternatively activated macrophages $(13,14)$. Broadly speaking, M1-activated macrophages are associated with inflammatory responses and are involved in fighting infections. This phenotype develops after exposure to microbial products, and proinflammatory cytokines such as tumor necrosis factor alpha $(\mathrm{TNF} \alpha)$ and interferon gamma (IFN $\gamma$ ). M2-activated macrophages are more difficult to capture into one phenotype, and this has led to the suggestion to group them into the different subsets M2a, M2b, and M2c (15). These subsets are associated with repair processes and resolution of inflammation and are induced by a variety of signals such as interleukin-4/interleukin-13 (IL-4/IL-13) for M2a, immune complexes and lipopolysaccharides (LPS) for M2b, and IL-10/ TGF $\beta$ /glucocorticosteroids for M2c. This classification had its uses for well-controlled in vitro experiments but could not capture the multitude or spectrum of polarization states present in vivo leading to much confusion in the field. This has led to the suggestion to identify macrophages through their origin, the polarizing substance, and/or markers they do or do not express (16).

The confusion about macrophage polarization is also apparent in the field of fibrosis. The widespread use of the M1/M2 classification has lead to the suggestion that M1 macrophages promote inflammation in the inflammatory stages of wound repair and subsequently polarize to or are being replaced by M2 macrophages that promote fibrosis. However, the complex microenvironment macrophages are exposed to in vivo has many stimuli that induce different functions that cannot be captured in M1 and M2. Furthermore, the M2 phenotype is a complex collection of divergent activities that are sometimes even contradictory. For example, in mice, M2 macrophages have been described by their expression of arginase-1 (Arg-1), and these macrophages were considered to be profibrotic. However, Pesce et al. showed, using macrophage-specific Arg-1-knockout mice, that these Arg-1-expressing macrophages were actually responsible for suppressing fibrosis development (17). This intriguing result shows the plasticity of profibrotic and antifibrotic behaviors within the M2 macrophage subset in a complex tissue environment.

Other studies have circumvented the M1/M2 dichotomy by naming macrophages after their roles in inflammation and tissue remodeling: i.e., proinflammatory, profibrotic, proresolution, resolving, or scar-associated macrophages (4, 10, 18-20). For the purpose of this review, we will be specifically addressing the macrophages that are associated with areas of existing fibrosis and are responsible for clearing away excess ECM, also known as proresolution or antifibrotic macrophages.

\section{MURINE VERSUS HUMAN MACROPHAGES}

The discovery of macrophages phenotypes has largely been driven by murine models. Translation to human steady-state conditions or diseases is scarce and hampered by the fact that many phenotypical and functional markers are murine-specific, and the human counterparts are unknown $(12,21)$. For instance, the widely used M2 markers Ym1 (chitinase 3-like protein 3) and FIZZ1 (resistin-like molecule alpha 1 /found in inflammatory zone 1) are only expressed on murine IL-4/IL-13-activated macrophages and not in their human counterparts. Though firmly 
associated with development of fibrosis in mouse models, how these markers themselves play a role is unclear (22-24), making it even more difficult find their human equivalents. Most of the information on antifibrotic macrophages will therefore be derived from murine studies. Whenever possible we will try to make the translation to the human situation.

\section{THE ORIGIN OF TISSUE MACROPHAGES}

Mature macrophages in adult tissues can originate from two different sources: either from circulating blood monocytes that infiltrate the tissues after birth or from embryonic macrophages infiltrating tissues before birth and that self-maintain throughout life (25-32). The distinction between hematopoetic versus embryonic origin may be important because this may determine their functionality (33). For instance, liver-resident alternatively activated macrophages were found to be phenotypically and functionally distinct from monocyte-derived alternatively activated macrophages. The first were found to be key in suppressing schistosomiasis-induced chronic inflammation, while the latter monocyte-derived ones could slow the progression of fibrosis (34).

Recent experiments have shown that during steady-state conditions, in most organs, tissue macrophages are of embryonic origin (25-32). These embryonic macrophages can develop from yolk sac macrophages directly or, through erythro-myeloid progenitors in the fetal liver $(25,30,35,36)$. In the developing embryo, hematopoiesis begins in the yolk sac with primitive erythrocytes and macrophages developing in the absence of hematopoietic stem cells and spreading into developing peripheral tissues (37). This primitive hematopoiesis is not sufficient to support the developing embryo until hematopoietic stem cells are functional. Therefore, a second wave of hematopoiesis is supported by erythro-myeloid progenitors migrating from the yolk sac to the fetal liver until the hematopoietic stem cells are ready to take over after birth (36). During this period of primitive hematopoiesis, macrophages spread via the blood into peripheral tissues of the fetus, giving rise to tissue-resident macrophages that self-maintain throughout life (38). Several organs including spleen, pancreas, and kidney exhibit mixed contribution from embryonic and hemopoietic stem cell-derived procursors (38). Like other tissue macrophages, intestinal macrophages are also first established before birth from embryonic precursors. However, unlike macrophages in most other tissues, these embryonic macrophages in the gut are replaced shortly after birth by blood monocyte-derived macrophages. Thus, intestinal macrophages appear to be entirely derived from circulating monocytes $(39,40)$. An overview of the origins of macrophages in the different tissues can be found in Table $\mathbf{1}$.

Resident tissue macrophages normally have homeostatic functions including clearing up debris and apoptotic cells, firstline defense against microbial threats, downregulating unnecessary inflammatory responses of the tissue, and contribution to normal ECM turnover. In cases of tissue damage, the steady-state conditions change, and the tissue-resident macrophages may be supplemented with macrophages derived from incoming monocytes to fight incoming threats and help wound healing. In mice, two populations of monocytes have been identified based
TABLE 1 | An overview of the origins of macrophages in the different tissues.

\begin{tabular}{lccl}
\hline $\begin{array}{l}\text { Tissue-resident } \\
\text { macrophages }\end{array}$ & \multicolumn{2}{c}{ Embryonic progenitor } & $\begin{array}{l}\text { Adult } \\
\text { hematopoietic } \\
\text { stem cells }\end{array}$ \\
\cline { 2 - 3 } & Yolk sac & $\begin{array}{r}\text { Fetal liver } \\
\text { monocytes }\end{array}$ & \\
\hline Spleen (27) & & $\sqrt{ }$ & $\sqrt{ }$ \\
$\begin{array}{l}\text { Pancreas (27) } \\
\text { Kidney(27) }\end{array}$ & $\sqrt{ }$ & $\sqrt{ }$ \\
$\begin{array}{l}\text { Brain (microglia) (41) } \\
\text { Heart (31) }\end{array}$ & $\sqrt{ }$ & $\sqrt{ }$ & $\sqrt{ }$ \\
$\begin{array}{l}\text { Skin (Langerhans cells) (30) } \\
\text { Skin (dermal macrophages) } \\
\text { (42, 43) }\end{array}$ & $\sqrt{ }$ & $\sqrt{ }$ & $\sqrt{ }$ (small number) \\
$\begin{array}{l}\text { Gut (39, 40) } \\
\text { Lung (alveolar macrophages) } \\
\text { (25) }\end{array}$ & & & $\sqrt{ }$ \\
Liver (Kupffer cell) (28, 44) & $\sqrt{ }$ & $\sqrt{ }$ & $\sqrt{ }$ \\
\hline
\end{tabular}

on the expression of the surface molecule lymphocyte antigen 6C (Ly6C). Monocytes with high expression of Ly6C are generally called classical or inflammatory monocytes, and these patrol the extravascular tissues in homeostatic conditions (29). During this patrolling function, they remain monocytic and do not commit to being macrophages. During inflammation, however, they respond with rapid extravasion into the affected tissues and they can readily transform into macrophages with limited potential for migration (29). Monocytes with low expression of Ly6C are called non-classical monocytes and patrol the blood vessels to monitor endothelial cell homeostasis $(45,46)$. They develop from the Ly6C-hi subset $(26,47,48)$, and this can also take place in injured or inflamed tissue with subsequent conversion to wound-healing macrophages that can proliferate locally $(49,50)$.

In humans, similar monocytes' subsets are found based on the expression of CD14 and CD16 (51). Classical monocytes express high levels of CD14 and no CD16, while non-classical monocytes express high levels of CD16 and low levels of CD14. Both in humans and mice, an intermediate third subset is suggested to exist characterized in humans by high levels of CD14 and intermediate levels of CD16. The functions of this subset are not well understood, although they have been found to preferentially accumulate in inflamed human livers and have been postulated to play a role in fibrogenesis (52).

Unfortunately, there are no reliable markers to distinguish between macrophages from embryonic or hematopoietic/monocytic origin, which makes it difficult to study the contributions of the two types of macrophages to changes in homeostatic conditions, especially in humans. In mice, some lineage-tracing studies have been performed with special mouse models in the context of fibrosis to get some insight into the origin of macrophages in fibrotic tissues, and these studies are discussed below.

\section{THE ORIGIN OF MACROPHAGES DURING FIBROSIS}

Several papers have investigated the various origins of macrophages in the context of fibrosis. There is a clear role for 
infiltrating Ly6C-hi monocytes in fibrosis. These monocytes have high expression of CCR2 (C-C motif chemokine receptor type 2) and have been shown to CCR2-dependently infiltrate the kidney, liver, heart, and lung after acute injury $(8,53-56)$. Less fibrosis is found when this migration is prevented either by specific depletion of the Ly6C-hi subset or by interfering with CCR2 function $(53,57)$. In liver and lung, it was shown that Ly6C-hi monocytes clearly facilitate the progression of fibrosis, but without obviously engrafting into the tissue as macrophages, which may indicate that their patrolling behavior of extravascular tissues is not restricted to steady-state conditions $(8,53)$.

Many models of fibrosis consist of toxic injury (e.g., carbon tetrachloride and bleomycin) with an acute inflammatory phase followed by a fibrotic phase and a resolution phase with a return to fairly normal tissue structure. In these models, it was shown that depletion of macrophages in the resolution phase slowed down the process of resolution $(8,18,57-62)$. These restorative macrophages appear to be derived from the recruited Ly6C-hi monocytes that undergo a phenotypic switch to a Ly6C-lo phenotype $(18,57)$. However, in a study by Baeck et al. inhibiting a transient CCR2-dependent accumulation of Ly6C-hi monocytes in the resolution phase accelerated scar resolution in two models of hepatic fibrosis (62). Therefore, contributions of both recruited Ly6C-lo monocytes and tissue-resident macrophages are also likely (8, 59-61). Corroboration for involvement of Ly6C-lo monocytes comes from a study showing that deletion of the fractalkine receptor $\mathrm{CX} 3 \mathrm{CR} 1$ (C-X3-C motif chemokine receptor 1), which is highly expressed on Ly6C-lo monocytes, inhibits resolution of hepatic fibrosis (60). Gibbons et al. showed that ablation of tissue-resident macrophages in the lung during the resolution phase of bleomycin-induced injury also slowed down resolution (8).

In conclusion, macrophages of various origins, hematopoietic and embryonic, contribute to fibrosis and its resolution. The evidence available points at antifibrotic macrophages being either derived from CX3CR1-expressing Ly6C-lo monocytes and/ or embryonically derived tissue-resident macrophages, while ly6C-hi monocytes appear to be profibrotic. For a summary of the available data also see Table 2.

\section{ANTIFIBROTIC MACROPHAGES: HOW TO IDENTIFY AND INDUCE OR RECRUIT THEM?}

Within fibrotic parts of tissues, higher numbers of macrophages were shown to be present as compared to the healthy parts, and

TABLE 2 | Origins of antifibrotic macrophages.

\begin{tabular}{lcc}
\hline Organ & \multicolumn{2}{c}{ Antifibrotic macrophages } \\
\cline { 2 - 3 } & Tissue resident & $\begin{array}{c}\text { Ly6C-lo-recruited } \\
\text { monocyte }\end{array}$ \\
\hline Peritoneal & $\sqrt{ }(63)$ & $\sqrt{ }(63)$ \\
Lung & $\sqrt{ }(8,64,65)$ & $\sqrt{ }(59,66)$ \\
Liver (Kupffer cell) & & $\sqrt{ }(60)$
\end{tabular}

these were shown to be important for fibrosis resolution $(61,67$, 68). One of the main tasks of these antifibrotic macrophages is clearance offibrotic ECM, in particular offibrillar types of collagen. Macrophages are important sources of various matrix-degrading enzymes, and they can take up partially degraded collagen fragments (6). The expression of these matrix-degrading enzymes and of the receptors for uptake of collagen fragments could therefore potentially be markers of antifibrotic macrophages in vivo.

Collagen fibers are cleaved extracellularly by proteases, such as MMPs and cathepsins. Intact fibrillar collagen can only be cleaved by a subset of MMPs (MMP1, MMP8, MMP13, and MMP14) and by other proteases, such as cathepsin K (69-71). Subsequently, collagen pieces are further degraded by other members of the MMP family like MMP2 and MMP9 (6). The main cellular source of matrix-degrading enzymes is macrophages. Huang et al. showed expression of different MMPs in the various macrophage phenotypes in vitro (72). Therefore, MMP expression by macrophages might serve as a functional marker to identify antifibrotic macrophages in vivo. Scar-associated macrophages were shown to be a source of MMP13 and a strong correlation between the presence of MMP13-positive macrophages, and enhanced regression was shown in fibrotic carbon tetrachloride mouse livers (68). Not only MMP13 but also other members of the MMP family (MMP3, MMP8, MMP9, MMP12, and MMP14) were identified in scarassociated macrophages and associated with resolution activities in liver $(73,74)$. The presence of MMP-expressing macrophages in scar tissue was also seen in other fibrotic tissues, such as lung, kidneys, heart, and spinal cord. Shechter et al. showed MMP13expressing macrophages in glial scar tissue and related this to a resolving macrophage phenotype (58). Cabrera et al. showed increased MMP9 expression in alveolar macrophages that appear in the regression phase of the bleomycin-induced lung fibrosis (75). Also, Popov et al. showed that MMP9, in contrast to MMP12 and MMP13, was particularly induced during resolution and higher expressed than during fibrogenesis (74). Within lung and liver, MMP9 expression is particularly observed in macrophages, as can be checked in immunohistochemical stainings provided by the human protein atlas (76).

In addition to MMPs, macrophages also express other ECM-degrading enzymes, such as the cysteine proteases, i.e., cathepsins (71). MMPs are traditionally considered to be the main agents of ECM degradation, but the lysosomal cathepsins can also be secreted into the extracellular space where they can remain proteolyticaly active and degrade various components of the ECM (71). Cathepsin K is the only protease with the ability to degrade intact fibrillar collagen, both at the ends of the fibril and at multiple sites within the triple helix. Overexpression of cathepsin K-protected animals from developing bleomycine or silica-induced pulmonary fibrosis, while deleting it accelerated the development of fibrosis $(66,77,78)$. These findings all suggest high antifibrotic activity of cathepsin $\mathrm{K}$, and therefore of macrophages in the lung. Alveolar macrophages in the resolution phase are also reported to produce plasmin, a protease associated with reducing TGF $\beta 1$ levels and thus with reduced stimulation of collagen synthesis (64).

Matrix metalloproteinases can also contribute to other activities, such as cellular migration (79) and activation of cytokines 
and growth factors $(80,81)$. The expressions and activities of MMPs are therefore not limited to the resolution phase. Certain subtypes are more enhanced during fibrogenesis as compared to resolution, e.g., MMP2 in liver fibrosis (74). This might hamper the use of certain MMPs as markers for antifibrotic macrophages. Based on the current knowledge about the expression patterns of matrix-degrading enzymes in macrophages in fibrosis and resolution, in particular MMP9, MMP13, and cathepsin K seem suitable markers to discern antifibrotic macrophages in vivo from other macrophage phenotypes.

In addition to the matrix-degrading activities of antifibrotic macrophages, candidate markers of antifibrotic macrophages could also be proteins involved in the induction of proteolytic enzymes and proteins involved in clearance of degraded ECM proteins. After extracellular degradation, further processing of collagen fragments occurs intracellularly, predominantly in the lysosomal compartments of the cell. To that end, collagen fragments are internalized via phagocytosis, macropinocytosis, or receptor-mediated endocytosis (6).

Phagocytosis, for instance, is mediated by binding of collagen fragments to cellular membrane integrin $\alpha 2 \beta 1$. For receptormediated endocytosis binding to transmembrane mannose receptor CD206 or mannose receptor 2 (Mrc2; also called Endo180) is required $(6,82-84)$. López -Guisa et al. showed upregulation of Mrc2 in a subset of macrophages at sites of renal fibrosis directing the process of repair. Renal fibrosis was significantly worse in Mrc2-deficient mice, which was related to lower collagen turnover. In addition, treatment of wild-type mice with a cathepsin inhibitor, which blocks the proteases implicated in Mrc2-mediated collagen degradation, worsened UUO-induced renal fibrosis (83).

The extracellular bridging glycoprotein Mfge8 (milk fat globule-EGF factor 8) has also been described to be involved in the cellular uptake of collagen fragments $(6,65,85)$. Atabai et al. showed that Mfge8 decreased the severity of tissue fibrosis in a mouse model of pulmonary fibrosis by binding and targeting collagen for cellular uptake through its discoidin domains (85). Reddy et al. showed that nitrated fatty acids regulated the expression of Mfge8 in alveolar macrophages and thus stimulated collagen uptake and its further degradation (65). The usefulness of these receptors, involved in the cellular uptake of collagen, in identifying antifibrotic macrophages has not been investigated in great detail and will require more studies.

Other proteins expressed by macrophages that have been shown to contribute to the antifibrotic phenotype of macrophages are Arg-1 (17) and FIZZ1 (22). Both were shown to limit Th2dependent responses that are required for the development of fibrosis.

As is clear from the previous sections, production of matrixdegrading enzymes is one of the key characteristics of antifibrotic macrophages. Therefore, to induce this type of macrophage, it will be helpful to understand the signals involved in attracting these macrophages to the fibrotic areas and/or the signals that induce the expression of matrix-degrading enzymes and collagen uptake receptors. These could be cytokines such as TNF $\alpha$, IL-1 $\beta$, IFN $\alpha / \beta$, and IL- 4 , growth factors, chemokines, or even processes $(58,81,86-88)$.
Popov et al. showed that the enhanced proteolytic activity of macrophages was induced after phagocytosis of apoptotic cholangiocytes that were increasingly present in the resolution phase of biliary fibrosis (74). The receptor involved in this phagocytosis-induced proteolytic activity was most probably the tyrosine-protein kinase Mer receptor (MERTK), which is highly expressed on macrophages $(74,89,90)$. Gene variants of MERTK have been shown to be risk factors for the progression of hepatitis C-induced liver fibrosis $(91,92)$. Through no functional data of the gene variants of MERTK were shown, making it hard to interpret this data. Similar phagocytosis-induced proteolytic activity was reported in the lung, in which apoptotic cell instillation induced peroxisome proliferator-activated receptor- $\gamma$ (PPAR $\gamma$ ) expression in macrophages and subsequently stimulated resolution of bleomycin-induced fibrosis (93). Whether MERTK and $\operatorname{PPAR} \gamma$ are useful markers for antifibrotic macrophages needs to be investigated in further detail. PPAR $\gamma$ seems to be a promising candidate as agonists of PPAR $\gamma$ have been investigated as a possible antifibrotic therapy in multiple settings $(65,94-100)$.

Some of the cytokines or their receptors that induce antifibrotic behavior are expressed by macrophages themselves; therefore these cytokines or their receptors could potentially also be markers of antifibrotic macrophages. However, their ubiquitous expression by various other cells may hamper their use in vivo.

Tumor necrosis factor alpha receptor $(\mathrm{TNF} \alpha \mathrm{R})$ or the production of TNF $\alpha$ may be potential inducers and/or markers of antifibrotic macrophages, though this depends on the stage of the disease limiting their use. Macrophages are important producers of $\mathrm{TNF} \alpha$ and thereby contribute to inflammation after injury. Inhibiting $\mathrm{TNF} \alpha$ at this point has been shown to lead to less fibrosis in models of kidney, liver, heart, and lung fibrosis (101-105). However, TNF $\alpha$ has also been shown to have antifibrotic activities, especially in the resolution stage of fibrosis. Recent research showed that intratracheal delivery of TNF $\alpha$ reduced lung collagen levels and improved lung architecture. In addition, mice deficient in $\mathrm{TNF} \alpha$ exhibited delayed resolution of bleomycin-induced pulmonary fibrosis, further showing that TNF $\alpha$ may be important in the resolution phase of fibrosis by inducing antifibrotic macrophages (106). A study in patients with pulmonary fibrosis showed that release of $\mathrm{TNF} \alpha$ by macrophages and monocytes of these patients was higher than of controls, which may be a sign that the lung is trying to degrade excess collagen or a sign that inflammation is still important in patients diagnosed with pulmonary fibrosis (107). The fact that anti-inflammatory drugs such as corticosteroids are harmful to pulmonary fibrosis patients indicates that TNF $\alpha$ is probably involved in attempted resolution (108). Production of TNF $\alpha$ by antifibrotic macrophages may have an effect on macrophages themselves through TNF $\alpha$ type 1 and/ or 2 receptors or affect other cells. Both in the heart and in the kidney, TNF $\alpha$ type 2 receptor expression on macrophages was found to essential for accelerating fibrosis resolution $(109,110)$. A recent publication by Lemos et al. showed that the effect of $\mathrm{TNF} \alpha$ in muscle fibrosis was through induction of apoptosis of myofibroblast progenitors (111).

Treatment of liver macrophages with interferon-a2b induced a higher MMP13 expression, and these macrophages also showed a higher expression of IL-10 (88). Similar findings were 
reported in glial scars by Shechter et al. (58). The effect of IL-10 on fibrosis, however, is not clear since increased levels of IL-10 were accompanied by reduced fibrosis in one study (73), while other studies have reported that IL-10 acts profibrotic (112, 113).

Cytokines and chemokines that are involved in recruitment antifibrotic macrophages are macrophage migration inhibitory factor (MIF), CX3C ligand 1 (fractalkine), and vascular endothelial growth factor (VEGF) $(60,61,114)$. CD74, CXCR2, and CXCR4 are receptors for MIF, and their expressions appear to be associated with recruitment of resolving macrophages $(61,115$, 116). This also is the case for chemokine receptor CX3CR1, and this receptor may also be helpful in the detection of antifibrotic macrophages (60). Another chemokine involved in the recruitment of resolution-promoting monocytes appears to be VEGF. Treatment with a neutralizing antibody against VEGF during fibrosis resolution delayed resolution, and this was shown to be dependent on CXCL9 and MMP13 (114). In addition, enhanced expression of CXCL10 in macrophages has been shown to accelerate resolution of pulmonary fibrosis $(59,117,118)$. Interestingly, in the study by Tighe et al., IFN $\gamma$ was found to be able to stimulate production of CXCL10 in macrophages, and this may therefore contribute to the known antifibrotic effects of $\operatorname{IFN} \gamma(59,119)$.

In conclusion, various studies indicate the existence of antifibrotic macrophages that play a key role in resolving fibrotic ECM, and therefore these macrophages may be a target for therapeutic intervention. Identification of this subset in vivo is not easy, but various options can be explored. One of the most obvious is the expression of matrix-degrading enzymes in macrophages, in particular, MMP9, MMP13, and cathepsin K. Other options include the chemokines CXCL10 and CXCL9, chemokine receptor CX3CR1, M2 markers Arg-1, FIZZ1, and PPAR $\gamma$, collagenuptake receptors MRC1, MRC2, and MFGE8, and cytokines like TNF $\alpha$ (see also Table 3). However, most of these proteins are not specific to macrophages and even the different phenotypes of macrophages in the proinflammatory/fibrotic phase and in the resolution phase seem to use them.

TABLE 3 | Markers of antifibrotic macrophages and potential therapeutic approaches inducing or attracting antifibrotic macrophages or inhibiting the recruitment of profibrotic monocytes.

\begin{tabular}{ll}
\hline Markers & Prospective drug \\
\hline TNF receptor $(109,110)$ & TNF $\alpha(106)$ \\
CX3CR1 $(60)$ & RANKL (122-124) \\
TNF $\alpha(106,107,111)$ & PPAR $\gamma$ agonist (93-100) \\
CXCL10 $(59,117,118)$ & IFN $\gamma(59,125)$ \\
CXCL9 $(117,118)$ & IFN $\alpha(58,88)$ \\
MMP9 $(73-75)$ & Asprin-triggered lipoxin A analogs (126) \\
MMP13 $(68,118)$ & CCL2 inhibitors (62) \\
Cathepsin K (66, 71, 77, 78) & \\
MERTK(89, 90) & \\
PPAR $\gamma(93-100)$ & \\
MRC1 $(120)$ & \\
MRC2 $(121)$ & \\
MFGE8 (6, 65, 85) & \\
Arg-1 (17) & \\
FIZZ1 (22)
\end{tabular}

Induction or recruitment of antifibrotic macrophages is even less well defined. Monocytes that turn into antifibrotic macrophages appear to be recruited by CX3C ligand 1 or VEGF. Cytokines that can induce antifibrotic behavior of macrophages in well-defined circumstances are TNF $\alpha, \operatorname{IFN} \alpha$, or IFN $\gamma$.

\section{FROM CONCEPT TO MARKET: THERAPEUTIC APPLICATIONS AND CHALLENGES}

As antifibrotic macrophages can be crucial in the resolution of fibrosis in various organs, they constitute a valid novel target for therapeutic intervention. Therefore, understanding of how to specifically induce their beneficial activities may lead to a generation of new antifibrotic compounds.

In addition to the aforementioned TNF $\alpha, \operatorname{IFN} \gamma$, and IFN $\alpha$, only a few potential therapeutic compounds affecting antifibrotic macrophages have been described in literature. One of the few examples is the use of PPAR $\gamma$ agonists that can induce antifibrotic properties in macrophages. Experimental studies in kidney, liver, heart, and lung have shown that various PPAR $\gamma$ agonists can alleviate fibrosis, though not all have investigated macrophages specifically $(65,94-100)$. There is even phase 1 safety study in clinicaltrials.gov describing the use of PPAR $\gamma$-agonist rosiglitazone for the treatment of focal glomerulosclerosis. This study ended in 2007, but no results have been posted yet.

A currently unexplored option is the possible use of receptor activator of nuclear factor- $\kappa \mathrm{B}$ ligand (RANKL). Many tissue macrophages express the receptor RANK for this ligand, and there are several studies showing that RANKL stimulation induces the release of proteases, which can degrade ECM (76). Wittrant et al. showed that RANKL stimulated MMP9 and cathepsin K expression (122), and Matsumoto et al. also showed that RANKL induced cathepsin K gene expression (123). Another study showed that RANKL, through binding to RANK, activated the nuclear factor- $\kappa \mathrm{B}$ pathway and induced MMP9 expression. They also suggested that by costimulating with IL- $1 \beta$ or TNF $\alpha$, it was possible to synergize with RANKL to further enhance MMP9 expression (124). We are currently investigating whether RANKL can indeed induce antifibrotic macrophages in settings of established fibrosis.

Another option described was the use of a Spiegelmer-based inhibitor of CCL2, named mNOX-E36, that was found to inhibit recruitment of Ly6C-hi monocytes and thereby accelerated resolution of liver fibrosis (62). The last of the few examples was a synthetic analog of asprin-triggered lipoxin A(4). Lipoxins have potent proresolution effects, and this synthetic analog called ATLa reversed collagen deposition by inducing Arg-1-positive macrophages in a bleomycin model of pulmonary fibrosis (126). A summary of the origin and all characteristics of antifibrotic macrophages is depicted in Figure 1.

One factor worth considering is the translation of these results in rodents to the human situation. As said before, an obstacle in this translation is that most knowledge so far is obtained with mouse models, and the markers and effector 


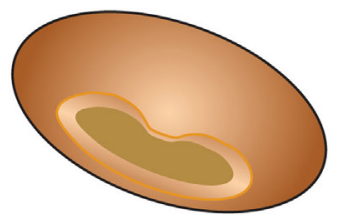

YOLK SAC MACROPHAGE

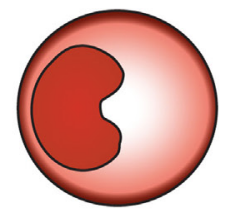

FETAL MONOCYTE
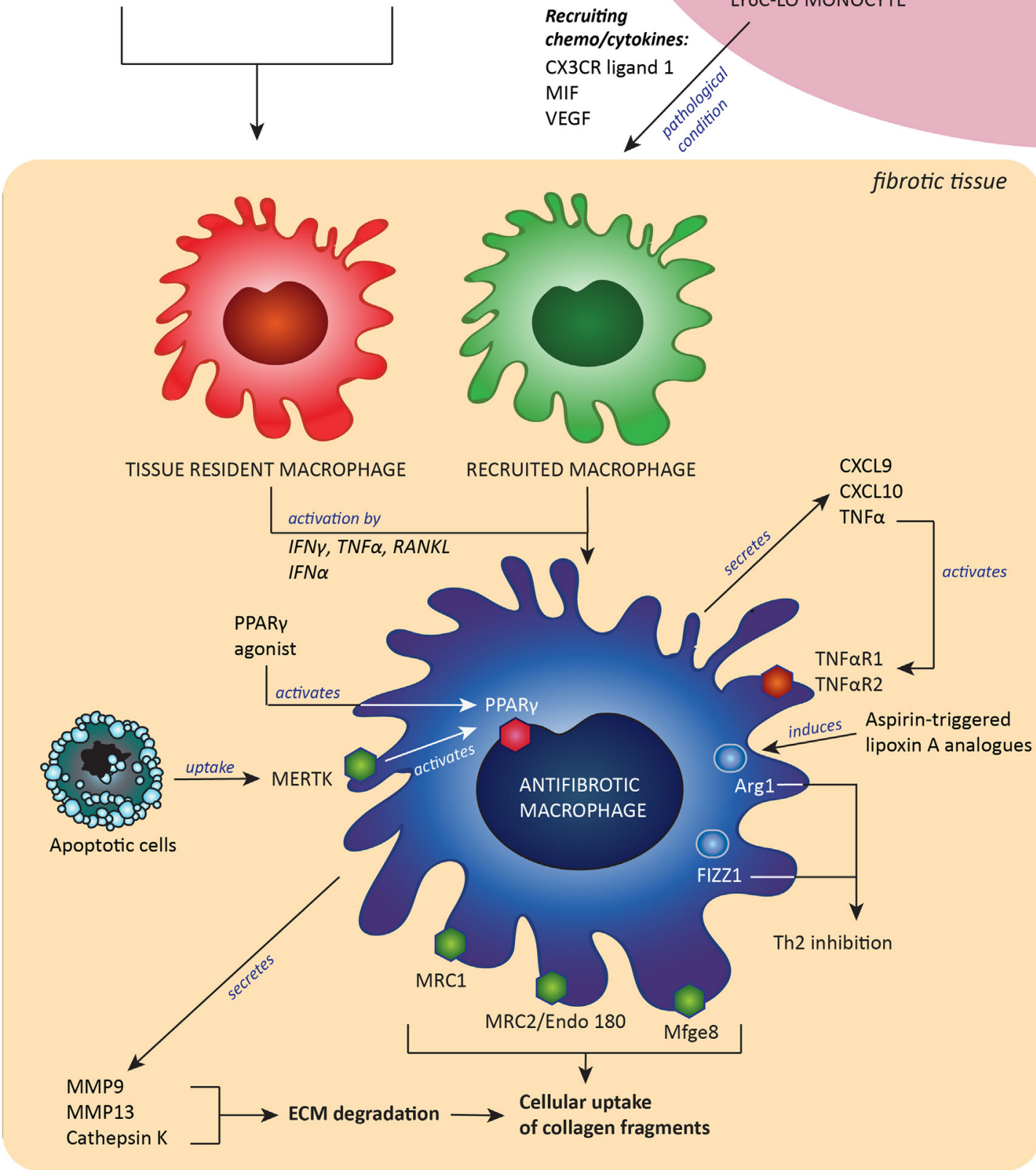

TISSUE RESIDENT MACROPHAGE

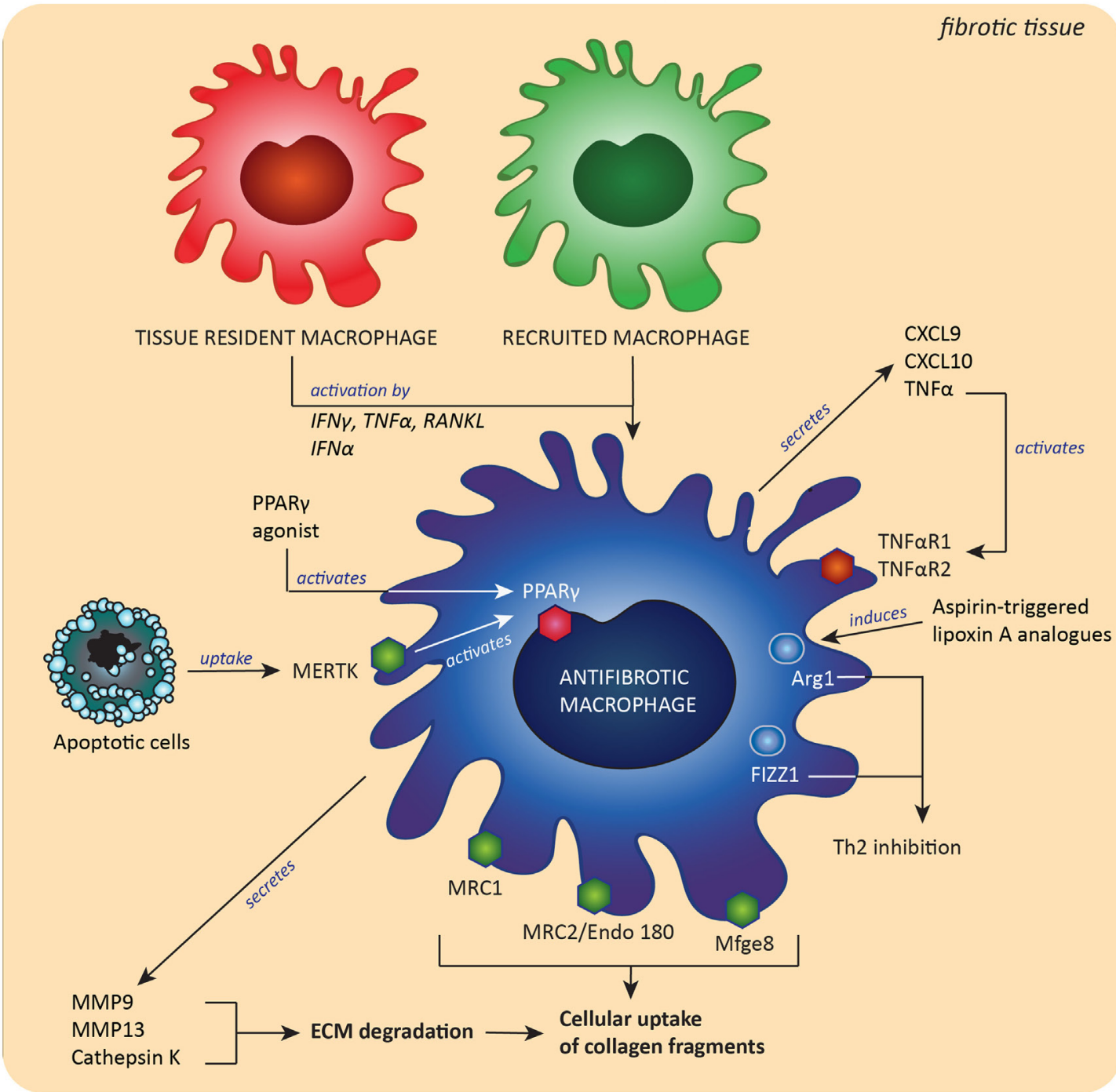

ED MACROPHAGE

Recruiting chemo/cytokines: CX3CR ligand 1 MIF VEGF

FIGURE 1 | Antifibrotic macrophages, derived from either embryonic tissue macrophages and/or Ly6C-lo monocytes, contribute to fibrosis resolution by expressing extracellular matrix (ECM)-degrading enzymes and receptors to take up pieces of degraded ECM and by expression of proteins that downregulate Th2-associated inflammation. These antifibrotic macrophages can be induced or attracted by a number of signals, such as cytokines, chemokines and growth factors. Abbreviations: MIF, macrophages migration inhibitory factor; CX3CR ligand 1, ligand for C-X3-C motif chemokine receptor 1; VEGF, vascular endothelial growth factor; CXCL9 and -10, C-X-C motif chemokine ligand-9 and -10; RANKL, receptor activator of nuclear factor-kB ligand; TNF $\alpha$, tumor necrosis factor $\alpha$; TNF $\alpha R 1 / 2$, tumor necrosis factor receptor type 1 or 2; IFN $\gamma$, interferon $\gamma$; IFN $\alpha$, interferon $\alpha$; MMP9 and MMP13, matrix metalloproteinases 9 and 13; Mfge8, milk fat globule-EGF factor 8; MERTK, tyrosine-protein kinase Mer receptor; Mrc1 and Mrc2, mannose receptors 1 and 2; PPAR $\gamma$, peroxisome proliferator-activated receptor- $\gamma$; Arg-1, arginase-1; FIZZ1, resistin-like molecule alpha 1; Th2, T helper 2 lymphocyted-mediated. 
molecules of antifibrotic macrophages in humans are largely unexplored (127).

In addition, several fibrosis-inducing agents, such as carbon tetrachloride, bleomycine, silica, and nutritional interventions, are highly effective in establishing advanced fibrosis in mice, but they do not represent key elements of human disease completely.

\section{CONCLUSION}

The flurry in new studies investigating antifibrotic behavior of macrophages in recent years has made the elusive antifibrotic macrophage slightly more tangible. This subset of macrophages appears to be derived from embryonic tissue-resident macrophage or recruited Ly6C-lo monocytes and expresses a variety of markers traditionally assigned to both M1 and M2 macrophages, including MMP9, MMP13, cathepsin K, CXCL10, CXCL9, CX3CR1, Arg-1, FIZZ1, PPAR $\gamma$, MRC1, MRC2, MFGE8, and $\mathrm{TNF} \alpha$. Although therapy aimed at the antifibrotic macrophage is still in its infancy, it is expected that more targets for therapeutic

\section{REFERENCES}

1. Wynn T. Cellular and molecular mechanisms of fibrosis. J Pathol (2008) 214:199-210. doi:10.1002/path.2277

2. Noble PW, Homer RJ. Back to the future: historical perspective on the pathogenesis of idiopathic pulmonary fibrosis. Am J Respir Cell Mol Biol (2005) 33:113-20. doi:10.1165/rcmb.F301

3. Wynn T, Ramalingam T. Mechanisms of fibrosis: therapeutic translation for fibrotic disease. Nat Med (2012) 18:1028-40. doi:10.1038/nm.2807

4. Pellicoro A, Ramachandran P, Iredale J, Fallowfield J. Liver fibrosis and repair: immune regulation of wound healing in a solid organ. Nat Rev Immunol (2014) 14:181-94. doi:10.1038/nri3623

5. Kong P, Christia P, Frangogiannis NG. The pathogenesis of cardiac fibrosis. Cell Mol Life Sci (2014) 71:549-74. doi:10.1007/s00018-013-1349-6

6. McKleroy W, Lee T-H, Atabai K. Always cleave up your mess: targeting collagen degradation to treat tissue fibrosis. Am J Physiol Lung Cell Mol Physiol (2013) 304:L709-21. doi:10.1152/ajplung.00418.2012

7. Barron L, Wynn TA. Fibrosis is regulated by Th2 and Th17 responses and by dynamic interactions between fibroblasts and macrophages. Am J Physiol Gastrointest Liver Physiol (2011) 300:G723-8. doi:10.1152/ ajpgi.00414.2010

8. Gibbons MA, MacKinnon AC, Ramachandran P, Dhaliwal K, Duffin R, Phythian-Adams AT, et al. Ly6Chi monocytes direct alternatively activated profibrotic macrophage regulation of lung fibrosis. Am J Respir Crit Care Med (2011) 184:569-81. doi:10.1164/rccm.201010-1719oc

9. Song E, Ouyang N, Hörbelt M, Antus B, Wang M, Exton MS. Influence of alternatively and classically activated macrophages on fibrogenic activities of human fibroblasts. Cell Immunol (2000) 204:19-28. doi:10.1006/ cimm. 2000.1687

10. Boorsma CE, Draijer C, Melgert BN. Macrophage heterogeneity in respiratory diseases. Mediators Inflamm (2013) 2013:769214. doi:10.1155/2013/769214

11. Duffield JS, Forbes SJ, Constandinou CM, Clay S, Partolina M, Vuthoori $\mathrm{S}$, et al. Selective depletion of macrophages reveals distinct, opposing roles during liver injury and repair. J Clin Invest (2005) 115:56-65. doi:10.1172/ JCI22675

12. Gordon S, Taylor PR. Monocyte and macrophage heterogeneity. Nat Rev Immunol (2005) 5:953-64. doi:10.1038/nri1733

13. Mills $\mathrm{CD}$. Anatomy of a discovery: $\mathrm{m} 1$ and $\mathrm{m} 2$ macrophages. Front Immunol (2015) 6:212. doi:10.3389/fimmu.2015.00212

14. Martinez FO, Gordon S. The M1 and M2 paradigm of macrophage activation: time for reassessment. F1000Prime Rep (2014) 6:13. doi:10.12703/P6-13

15. Martinez FO, Sica A, Mantovani A, Locati M. Macrophage activation and polarization. Front Biosci (2008) 13:453-61. doi:10.2741/2692 entities will appear when antifibrotic macrophages are better understood.

\section{AUTHOR CONTRIBUTIONS}

$\mathrm{AA}$ and KP collected data, summarized findings, wrote the manuscript, and designed the figure; LB interpreted findings described in literature, rewrote parts of the text, provided critical comments, and reviewed and approved the manuscript; and BM designed the outline of the review, interpreted findings described in literature, rewrote parts of the text, provided critical comments, and reviewed and approved the manuscript.

\section{FUNDING}

We gratefully acknowledge funding by an LPDP scholarship of the Indonesian government (AA) and an Ubbo Emmius scholarship of the University of Groningen in collaboration with Universitas Indonesia (KP).

16. Murray PJ, Allen JE, Biswas SK, Fisher EA, Gilroy DW, Goerdt S, et al. Macrophage activation and polarization: nomenclature and experimental guidelines. Immunity (2014) 41:14-20. doi:10.1016/j.immuni.2014.06.008

17. Pesce JT, Ramalingam TR, Mentink-Kane MM, Wilson MS, El Kasmi KC, Smith AM, et al. Arginase-1-expressing macrophages suppress Th2 cytokine-driven inflammation and fibrosis. PLoS Pathog (2009) 5:e1000371. doi:10.1371/journal.ppat.1000371

18. Ramachandran P, Pellicoro A, Vernon M, Boulter L, Aucott R, Ali A, et al. Differential $L y$-6C expression identifies the recruited macrophage phenotype, which orchestrates the regression of murine liver fibrosis. Proc Natl Acad Sci US A (2012) 109:E3186-95. doi:10.1073/pnas.1119964109

19. Wynn T, Chawla A, Pollard J. Macrophage biology in development, homeostasis and disease. Nature (2013) 496:445-55. doi:10.1038/nature12034

20. Anders H-J, Ryu M. Renal microenvironments and macrophage phenotypes determine progression or resolution of renal inflammation and fibrosis. Kidney Int (2011) 80:915-25. doi:10.1038/ki.2011.217

21. Wermuth PJ, Jimenez SA. The significance of macrophage polarization subtypes for animal models of tissue fibrosis and human fibrotic diseases. Clin Transl Med (2015) 4:2. doi:10.1186/s40169-015-0047-4

22. Pesce JT, Ramalingam TR, Wilson MS, Mentink-Kane MM, Thompson RW, Cheever AW, et al. Retnla (relmalpha/fizz1) suppresses helminth-induced Th2-type immunity. PLoS Pathog (2009) 5:e1000393. doi:10.1371/journal. ppat. 1000393

23. Madala SK, Edukulla R, Davis KR, Schmidt S, Davidson C, Kitzmiller JA, et al. Resistin-like molecule $\alpha 1$ (Fizz1) recruits lung dendritic cells without causing pulmonary fibrosis. Respir Res (2012) 13:51. doi:10.1186/1465-9921-13-51

24. Liu $\mathrm{T}, \mathrm{Yu} \mathrm{H}$, Ullenbruch $\mathrm{M}$, Jin $\mathrm{H}$, Ito $\mathrm{T}$, $\mathrm{Wu} \mathrm{Z}$, et al. The in vivo fibrotic role of FIZZ1 in pulmonary fibrosis. PLoS One (2014) 9:e88362. doi:10.1371/ journal.pone.0088362

25. Guilliams M, De Kleer I, Henri S, Post S, Vanhoutte L, De Prijck S, et al. Alveolar macrophages develop from fetal monocytes that differentiate into long-lived cells in the first week of life via GM-CSF. J Exp Med (2013) 210:1977-92. doi:10.1084/jem.20131199

26. Yona S, Kim K-W, Wolf Y, Mildner A, Varol D, Breker M, et al. Fate mapping reveals origins and dynamics of monocytes and tissue macrophages under homeostasis. Immunity (2013) 38:79-91. doi:10.1016/j.immuni.2012.12.001

27. Hashimoto D, Chow A, Noizat C, Teo P, Beasley M, Leboeuf M, et al. Tissueresident macrophages self-maintain locally throughout adult life with minimal contribution from circulating monocytes. Immunity (2013) 38:792-804. doi:10.1016/j.immuni.2013.04.004

28. Schulz C, Gomez Perdiguero E, Chorro L, Szabo-Rogers H, Cagnard N, Kierdorf $\mathrm{K}$, et al. A lineage of myeloid cells independent of Myb and hematopoietic stem cells. Science (2012) 336:86-90. doi:10.1126/science.1219179 
29. Jakubzick C, Gautier EL, Gibbings SL, Sojka DK, Schlitzer A, Johnson TE, et al. Minimal differentiation of classical monocytes as they survey steady-state tissues and transport antigen to lymph nodes. Immunity (2013) 39:599-610. doi:10.1016/j.immuni.2013.08.007

30. Hoeffel G, Wang Y, Greter M, See P, Teo P, Malleret B, et al. Adult Langerhans cells derive predominantly from embryonic fetal liver monocytes with a minor contribution of yolk sac-derived macrophages. J Exp Med (2012) 209:1167-81. doi:10.1084/jem.20120340

31. Epelman S, Lavine KJ, Beaudin AE, Sojka DK, Carrero JA, Calderon B, et al. Embryonic and adult-derived resident cardiac macrophages are maintained through distinct mechanisms at steady state and during inflammation. Immunity (2014) 40:91-104. doi:10.1016/j.immuni.2013.11.019

32. Epelman S, Lavine KJ, Randolph GJ. Origin and functions of tissue macrophages. Immunity (2014) 41:21-35. doi:10.1016/j.immuni.2014.06.013

33. Gundra UM, Girgis NM, Ruckerl D, Jenkins S, Ward LN, Kurtz ZD, et al. Alternatively activated macrophages derived from monocytes and tissue macrophages are phenotypically and functionally distinct. Blood (2014) 123:e110-22. doi:10.1182/blood-2013-08-520619

34. Vannella KM, Barron L, Borthwick LA, Kindrachuk KN, Narasimhan PB, Hart KM, et al. Incomplete deletion of IL-4R $\alpha$ by LysM(Cre) reveals distinct subsets of M2 macrophages controlling inflammation and fibrosis in chronic schistosomiasis. PLoS Pathog (2014) 10:e1004372. doi:10.1371/journal. ppat. 1004372

35. Hoeffel G, Chen J, Lavin Y, Low D, Almeida F, See P, et al. C-Myb+ erythro-myeloid progenitor-derived fetal monocytes give rise to adult tissue-resident macrophages. Immunity (2015) 42(4):665-78. doi:10.1016/j. immuni.2015.03.011

36. McGrath KE, Frame JM, Fegan KH, Bowen JR, Conway SJ, Catherman SC, et al. Distinct sources of hematopoietic progenitors emerge before HSCs and provide functional blood cells in the mammalian embryo. Cell Rep (2015) 11:1892-904. doi:10.1016/j.celrep.2015.05.036

37. Palis J. Primitive and definitive erythropoiesis in mammals. Front Physiol (2014) 5:3. doi:10.3389/fphys.2014.00003

38. Hashimoto D, Miller J, Merad M. Dendritic cell and macrophage heterogeneity in vivo. Immunity (2011) 35(3):323-35. doi:10.1016/j.immuni.2011.09.007

39. Bogunovic M, Ginhoux F, Helft J, Shang L, Hashimoto D, Greter M, et al. Origin of the lamina propria dendritic cell network. Immunity (2009) 31:513-25. doi:10.1016/j.immuni.2009.08.010

40. Gross M, Salame T-M, Jung S. Guardians of the gut - murine intestinal macrophages and dendritic cells. Front Immunol (2015) 6:254. doi:10.3389/ fimmu.2015.00254

41. Ginhoux F, Lim S, Hoeffel G, Low D, Huber T. Origin and differentiation of microglia. Front Cell Neurosci (2013) 7:45. doi:10.3389/fncel.2013.00045

42. Haniffa M, Ginhoux F, Wang X-N, Bigley V, Abel M, Dimmick I, et al. Differential rates of replacement of human dermal dendritic cells and macrophages during hematopoietic stem cell transplantation. J Exp Med (2009) 206:371-85. doi: $10.1084 /$ jem.20081633

43. Tamoutounour S, Guilliams M, Montanana Sanchis F, Liu H, Terhorst D, Malosse C, et al. Origins and functional specialization of macrophages and of conventional and monocyte-derived dendritic cells in mouse skin. Immunity (2013) 39:925-38. doi:10.1016/j.immuni.2013.10.004

44. Perdiguero E, Klapproth K, Schulz C, Busch K, Azzoni E, Crozet L, et al. Tissue-resident macrophages originate from yolk-sac-derived erythro-myeloid progenitors. Nature (2015) 518:547-51. doi:10.1038/nature13989

45. Carlin LM, Stamatiades EG, Auffray C, Hanna RN, Glover L, Vizcay-Barrena $\mathrm{G}$, et al. Nr4a1-dependent Ly6C(low) monocytes monitor endothelial cells and orchestrate their disposal. Cell (2013) 153:362-75. doi:10.1016/j. cell.2013.03.010

46. Auffray C, Fogg D, Garfa M, Elain G, Join-Lambert O, Kayal S, et al. Monitoring of blood vessels and tissues by a population of monocytes with patrolling behavior. Science (2007) 317:666-70. doi:10.1126/science.1142883

47. Hettinger J, Richards DM, Hansson J, Barra MM, Joschko A-C, Krijgsveld J, et al. Origin of monocytes and macrophages in a committed progenitor. Nat Immunol (2013) 14:821-30. doi:10.1038/ni.2638

48. Hanna RN, Carlin LM, Hubbeling HG, Nackiewicz D, Green AM, Punt JA, et al. The transcription factor NR4A1 (Nur77) controls bone marrow differentiation and the survival of Ly6C- monocytes. Nat Immunol (2011) 12:778-85. doi:10.1038/ni.2063
49. Arnold L, Henry A, Poron F, Baba-Amer Y, van Rooijen N, Plonquet A, et al. Inflammatory monocytes recruited after skeletal muscle injury switch into antiinflammatory macrophages to support myogenesis. J Exp Med (2007) 204:1057-69. doi:10.1084/jem.20070075

50. Hilgendorf I, Gerhardt LM, Tan TC, Winter C, Holderried TA, Chousterman BG, et al. Ly-6Chigh monocytes depend on Nr4al to balance both inflammatory and reparative phases in the infarcted myocardium. Circ Res (2014) 114:1611-22. doi:10.1161/CIRCRESAHA.114.303204

51. Ingersoll MA, Spanbroek R, Lottaz C, Gautier EL, Frankenberger M, Hoffmann R, et al. Comparison of gene expression profiles between human and mouse monocyte subsets. Blood (2010) 115:e10-9. doi:10.1182/ blood-2009-07-235028

52. Liaskou E, Zimmermann HW, Li K-K, Oo YH, Suresh S, Stamataki Z, et al. Monocyte subsets in human liver disease show distinct phenotypic and functional characteristics. Hepatology (2013) 57:385-98. doi:10.1002/hep.26016

53. Karlmark KR, Weiskirchen R, Zimmermann HW, Gassler N, Ginhoux F, Weber C, et al. Hepatic recruitment of the inflammatory Gr1+ monocyte subset upon liver injury promotes hepatic fibrosis. Hepatology (2009) 50:261-74. doi:10.1002/hep.22950

54. Lin SL, Castaño AP, Nowlin BT, Lupher ML, Duffield JS. Bone marrow Ly6Chigh monocytes are selectively recruited to injured kidney and differentiate into functionally distinct populations. J Immunol (2009) 183:6733-43. doi:10.4049/jimmunol.0901473

55. Falkenham A, de Antueno R, Rosin N, Betsch D, Lee TD, Duncan R, et al. Nonclassical resident macrophages are important determinants in the development of myocardial fibrosis. Am J Pathol (2015) 185:927-42. doi:10.1016/j. ajpath.2014.11.027

56. Ji W-J, Ma Y-Q, Zhou X, Zhang Y-D, Lu R-Y, Sun H-Y, et al. Temporal and spatial characterization of mononuclear phagocytes in circulating, lung alveolar and interstitial compartments in a mouse model of bleomycin-induced pulmonary injury. J Immunol Methods (2014) 403:7-16. doi:10.1016/j. jim.2013.11.012

57. Mitchell C, Couton D, Couty J-P, Anson M, Crain A-M, Bizet V, et al. Dual role of CCR2 in the constitution and the resolution of liver fibrosis in mice. Am J Pathol (2009) 174:1766-75. doi:10.2353/ajpath.2009.080632

58. Shechter R, Raposo C, London A, Sagi I, Schwartz M. The glial scar-monocyte interplay: a pivotal resolution phase in spinal cord repair. PLoS One (2011) 6:e27969. doi:10.1371/journal.pone.0027969

59. Tighe RM, Liang J, Liu N, Jung Y, Jiang D, Gunn MD, et al. Recruited exudative macrophages selectively produce CXCL10 after noninfectious lung injury. Am J Respir Cell Mol Biol (2011) 45:781-8. doi:10.1165/rcmb.2010-0471OC

60. Karlmark KR, Zimmermann HW, Roderburg C, Gassler N, Wasmuth HE, Luedde $\mathrm{T}$, et al. The fractalkine receptor CX-CR1 protects against liver fibrosis by controlling differentiation and survival of infiltrating hepatic monocytes. Hepatology (2010) 52:1769-82. doi:10.1002/hep.23894

61. Barnes MA, McMullen MR, Roychowdhury S, Madhun NZ, Niese K, Olman MA, et al. Macrophage migration inhibitory factor is required for recruitment of scar-associated macrophages during liver fibrosis. J Leukoc Biol (2015) 97:161-9. doi:10.1189/jlb.3A0614-280R

62. Baeck C, Wei X, Bartneck M, Fech V, Heymann F, Gassler N, et al. Pharmacological inhibition of the chemokine C-C motif chemokine ligand 2 (monocyte chemoattractant protein 1 ) accelerates liver fibrosis regression by suppressing $L y$-6C(+) macrophage infiltration in mice. Hepatology (2014) 59:1060-72. doi:10.1002/hep.26783

63. Stout R, Jiang C, Matta B, Tietzel I, Watkins S, Suttles J. Macrophages sequentially change their functional phenotype in response to changes in microenvironmental influences. J Immunol (2005) 175:342-9. doi:10.4049/ jimmunol.175.1.342

64. Khalil N, Corne S, Whitman C, Yacyshyn H. Plasmin regulates the activation of cell-associated latent TGF-beta 1 secreted by rat alveolar macrophages after in vivo bleomycin injury. Am J Respir Cell Mol Biol (1996) 15:252-9. doi:10.1165/ajrcmb.15.2.8703482

65. Reddy AT, Lakshmi SP, Zhang Y, Reddy RC. Nitrated fatty acids reverse pulmonary fibrosis by dedifferentiating myofibroblasts and promoting collagen uptake by alveolar macrophages. FASEB J (2014) 28:5299-310. doi:10.1096/ fj.14-256263

66. Srivastava M, Steinwede K, Kiviranta R, Morko J, Hoymann H-G, Länger F, et al. Overexpression of cathepsin $\mathrm{K}$ in mice decreases collagen deposition 
and lung resistance in response to bleomycin-induced pulmonary fibrosis. Respir Res (2008) 9:54. doi:10.1186/1465-9921-9-54

67. Beljaars L, Schippers M, Reker-Smit C, Martinez FO, Helming L, Poelstra $\mathrm{K}$, et al. Hepatic localization of macrophage phenotypes during fibrogenesis and resolution of fibrosis in mice and humans. Front Immunol (2014) 5:430. doi:10.3389/fimmu.2014.00430

68. Fallowfield JA, Mizuno M, Kendall TJ, Constandinou CM, Benyon RC, Duffield JS, et al. Scar-associated macrophages are a major source of hepatic matrix metalloproteinase-13 and facilitate the resolution of murine hepatic fibrosis. J Immunol (2007) 178:5288-95. doi:10.4049/jimmunol.178.8.5288

69. Borel O, Gineyts E, Bertholon C, Garnero P. Cathepsin K preferentially solubilizes matured bone matrix. Calcif Tissue Int (2012) 91:32-9. doi:10.1007/ s00223-012-9604-7

70. Costa AG, Cusano NE, Silva BC, Cremers S, Bilezikian JP. Cathepsin K: its skeletal actions and role as a therapeutic target in osteoporosis. Nat Rev Rheumatol (2011) 7:447-56. doi:10.1038/nrrheum.2011.77

71. Fonović M, Turk B. Cysteine cathepsins and extracellular matrix degradation. Biochim Biophys Acta (2014) 1840:2560-70. doi:10.1016/j. bbagen.2014.03.017

72. Huang W-C, Sala-Newby GB, Susana A, Johnson JL, Newby AC. Classical macrophage activation up-regulates several matrix metalloproteinases through mitogen activated protein kinases and nuclear factor-kB. PLoS One (2012) 7:e42507. doi:10.1371/journal.pone.0042507

73. Thomas JA, Pope C, Wojtacha D, Robson AJ, Gordon-Walker TT, Hartland $\mathrm{S}$, et al. Macrophage therapy for murine liver fibrosis recruits host effector cells improving fibrosis, regeneration, and function. Hepatology (2011) 53:2003-15. doi:10.1002/hep.24315

74. Popov Y, Sverdlov DY, Bhaskar KR, Sharma AK, Millonig G, Patsenker E, et al. Macrophage-mediated phagocytosis of apoptotic cholangiocytes contributes to reversal of experimental biliary fibrosis. Am J Physiol Gastrointest Liver Physiol (2010) 298:G323-34. doi:10.1152/ajpgi.00394.2009

75. Cabrera S, Gaxiola M, Arreola JL, Ramírez R, Jara P, D’Armiento J, et al. Overexpression of MMP9 in macrophages attenuates pulmonary fibrosis induced by bleomycin. Int J Biochem Cell Biol (2007) 39:2324-38. doi:10.1016/j.biocel.2007.06.022

76. Uhlén M, Fagerberg L, Hallström BM, Lindskog C, Oksvold P, Mardinoglu A, et al. Proteomics. Tissue-based map of the human proteome. Science (2015) 347:1260419. doi:10.1126/science.1260419

77. Van den Brûle S, Misson P, Bühling F, Lison D, Huaux F. Overexpression of cathepsin K during silica-induced lung fibrosis and control by TGF-beta. Respir Res (2005) 6:84. doi:10.1186/1465-9921-6-84

78. Bühling F, Röcken C, Brasch F, Hartig R, Yasuda Y, Saftig P, et al. Pivotal role of cathepsin K in lung fibrosis. Am J Pathol (2004) 164:2203-16. doi:10.1016/ S0002-9440(10)63777-7

79. Gong Y, Hart E, Shchurin A, Hoover-Plow J. Inflammatory macrophage migration requires MMP-9 activation by plasminogen in mice. J Clin Invest (2008) 118:3012-24. doi:10.1172/JCI32750

80. Rohani MG, Parks WC. Matrix remodeling by MMPs during wound repair. Matrix Biol (2015) 44-46C:113-21. doi:10.1016/j.matbio.2015.03.002

81. Sternlicht MD, Werb Z. How matrix metalloproteinases regulate cell behavior. Annu Rev Cell Dev Biol (2001) 17:463-516. doi:10.1146/annurev. cellbio.17.1.463

82. Engelholm LH, List K, Netzel-Arnett S, Cukierman E, Mitola DJ, Aaronson $\mathrm{H}$, et al. uPARAP/Endo180 is essential for cellular uptake of collagen and promotes fibroblast collagen adhesion. J Cell Biol (2003) 160:1009-15. doi:10.1083/jcb.200211091

83. López-Guisa JM, Cai X, Collins SJ, Yamaguchi I, Okamura DM, Bugge TH, et al. Mannose receptor 2 attenuates renal fibrosis. J Am Soc Nephrol (2012) 23:236-51. doi:10.1681/ASN.2011030310

84. Boskovic J, Arnold JN, Stilion R, Gordon S, Sim RB, Rivera-Calzada A, et al. Structural model for the mannose receptor family uncovered by electron microscopy of Endo180 and the mannose receptor. J Biol Chem (2006) 281:8780-7. doi:10.1074/jbc.M513277200

85. Atabai K, Jame S, Azhar N, Kuo A, Lam M, McKleroy W, et al. Mfge8 diminishes the severity of tissue fibrosis in mice by binding and targeting collagen for uptake by macrophages. J Clin Invest (2009) 119:3713-22. doi:10.1172/ JCI40053

86. Creasy BM, McCoy KL. Cytokines regulate cysteine cathepsins during TLR responses.CellImmunol(2011) 267:56-66.doi:10.1016/j.cellimm.2010.11.004
87. Balce DR, Li B, Allan ER, Rybicka JM, Krohn RM, Yates RM. Alternative activation of macrophages by IL- 4 enhances the proteolytic capacity of their phagosomes through synergistic mechanisms. Blood (2011) 118:4199-208. doi:10.1182/blood-2011-01-328906

88. YuZ, Xie M, FanX, Jia J.Interferon $\alpha 2$ b increases MMP-13 and IL-10 expression in Kupffer cells through MAPK signaling pathways. Hepatogastroenterology (2015) 62:350-4.

89. Sather S, Kenyon KD, Lefkowitz JB, Liang X, Varnum BC, Henson PM, et al. A soluble form of the Mer receptor tyrosine kinase inhibits macrophage clearance of apoptotic cells and platelet aggregation. Blood (2007) 109:1026-33. doi:10.1182/blood-2006-05-021634

90. Zagórska A, Través PG, Lew ED, Dransfield I, Lemke G. Diversification of TAM receptor tyrosine kinase function. Nat Immunol (2014) 15:920-8. doi:10.1038/ni.2986

91. Rüeger S, Bochud P-Y, Dufour J-F, Müllhaupt B, Semela D, Heim MH, et al. Impact of common risk factors of fibrosis progression in chronic hepatitis $\mathrm{C}$. Gut (2014) 64(10):1605-15. doi:10.1136/gutjnl-2014-306997

92. Patin E, Kutalik Z, Guergnon J, Bibert S, Nalpas B, Jouanguy E, et al. Genomewide association study identifies variants associated with progression of liver fibrosis from HCV infection. Gastroenterology (2012) 143:1244-52.e1_12. doi:10.1053/j.gastro.2012.07.097

93. Yoon Y-S, Kim S-Y, Kim M-J, Lim J-H, Cho M-S, Kang JL. PPAR $\gamma$ activation following apoptotic cell instillation promotes resolution of lung inflammation and fibrosis via regulation of efferocytosis and proresolving cytokines. Mucosal Immunol (2015) 8(5):1031-46. doi:10.1038/mi.2014.130

94. Kawai T, Masaki T, Doi S, Arakawa T, Yokoyama Y, Doi T, et al. PPAR-gamma agonist attenuates renal interstitial fibrosis and inflammation through reduction of TGF-beta. Lab Invest (2009) 89:47-58. doi:10.1038/labinvest.2008.104

95. Uto H, Nakanishi C, Ido A, Hasuike S, Kusumoto K, Abe H, et al. The peroxisome proliferator-activated receptor-gamma agonist, pioglitazone, inhibits fat accumulation and fibrosis in the livers of rats fed a choline-deficient, 1-amino acid-defined diet. Hepatol Res (2005) 32:235-42. doi:10.1016/j. hepres.2005.05.008

96. Ihm S-H, Chang K, Kim H-Y, Baek SH, Youn H-J, Seung K-B, et al. Peroxisome proliferator-activated receptor-gamma activation attenuates cardiac fibrosis in type 2 diabetic rats: the effect of rosiglitazone on myocardial expression of receptor for advanced glycation end products and of connective tissue growth factor. Basic Res Cardiol (2010) 105:399-407. doi:10.1007/ s00395-009-0071-x

97. Higashi K, Oda T, Kushiyama T, Hyodo T, Yamada M, Suzuki S, et al. Additive antifibrotic effects of pioglitazone and candesartan on experimental renal fibrosis in mice. Nephrology (Carlton) (2010) 15:327-35. doi:10.1111/j.1440-1797.2009.01253.x

98. Yang L, Stimpson SA, Chen L, Wallace Harrington W, Rockey DC. Effectiveness of the PPAR $\gamma$ agonist, GW570, in liver fibrosis. Inflamm Res (2010) 59:1061-71. doi:10.1007/s00011-010-0226-0

99. Wei J, Zhu H, Komura K, Lord G, Tomcik M, Wang W, et al. A synthetic PPAR- $\gamma$ agonist triterpenoid ameliorates experimental fibrosis: PPAR$\gamma$-independent suppression of fibrotic responses. Ann Rheum Dis (2014) 73:446-54. doi:10.1136/annrheumdis-2012-202716

100. Attia YM, Elalkamy EF, Hammam OA, Mahmoud SS, El-Khatib AS. Telmisartan, an AT1 receptor blocker and a PPAR gamma activator, alleviates liver fibrosis induced experimentally by Schistosoma mansoni infection. Parasit Vectors (2013) 6:199. doi:10.1186/1756-3305-6-199

101. Piguet PF, Vesin C. Treatment by human recombinant soluble TNF receptor of pulmonary fibrosis induced by bleomycin or silica in mice. Eur Respir $J$ (1994) 7:515-8. doi:10.1183/09031936.94.07030515

102. Kitamura K, Nakamoto Y, Akiyama M, Fujii C, Kondo T, Kobayashi K, et al. Pathogenic roles of tumor necrosis factor receptor p55-mediated signals in dimethylnitrosamine-induced murine liver fibrosis. Lab Invest (2002) 82:571-83. doi:10.1038/labinvest.3780452

103. Rojanasakul Y, Weissman DN, Shi X, Castranova V, Ma JK, Liang W. Antisense inhibition of silica-induced tumor necrosis factor in alveolar macrophages. $J$ Biol Chem (1997) 272:3910-4. doi:10.1074/jbc.272.7.3910

104. Gurantz D, Cowling RT, Varki N, Frikovsky E, Moore CD, Greenberg BH. IL-1beta and TNF-alpha upregulate angiotensin II type 1 (AT1) receptors on cardiac fibroblasts and are associated with increased AT1 density in the post-MI heart. J Mol Cell Cardiol (2005) 38:505-15. doi:10.1016/j. yjmcc.2004.12.015 
105. Meldrum KK, Misseri R, Metcalfe P, Dinarello CA, Hile KL, Meldrum DR. TNF-alpha neutralization ameliorates obstruction-induced renal fibrosis and dysfunction. Am J Physiol Regul Integr Comp Physiol (2007) 292:R1456-64. doi:10.1152/ajpregu.00620.2005

106. Redente EF, Keith RC, Janssen W, Henson PM, Ortiz LA, Downey GP, et al. Tumor necrosis factor- $\alpha$ accelerates the resolution of established pulmonary fibrosis in mice by targeting profibrotic lung macrophages. Am J Respir Cell Mol Biol (2014) 50:825-37. doi:10.1165/rcmb.2013-0386oc

107. Zhang Y, Lee TC, Guillemin B, Yu MC, Rom WN. Enhanced IL-1 beta and tumor necrosis factor-alpha release and messenger RNA expression in macrophages from idiopathic pulmonary fibrosis or after asbestos exposure. J Immunol (1993) 150:4188-96.

108. Woodcock HV, Maher TM. The treatment of idiopathic pulmonary fibrosis. F1000Prime Rep (2014) 6:16. doi:10.12703/P6-16

109. Hamid T, Gu Y, Ortines RV, Bhattacharya C, Wang G, Xuan Y-T, et al. Divergent tumor necrosis factor receptor-related remodeling responses in heart failure: role of nuclear factor-kappaB and inflammatory activation. Circulation (2009) 119:1386-97. doi:10.1161/CIRCULATIONAHA.108.802918

110. Morimoto Y, Gai Z, Tanishima H, Kawakatsu M, Itoh S, Hatamura I, et al. TNF-alpha deficiency accelerates renal tubular interstitial fibrosis in the late stage of ureteral obstruction. Exp Mol Pathol (2008) 85:207-13. doi:10.1016/j. yexmp.2008.08.003

111. Lemos DR, Babaeijandaghi F, Low M, Chang C-K, Lee ST, Fiore D, et al. Nilotinib reduces muscle fibrosis in chronic muscle injury by promoting TNF-mediated apoptosis of fibro/adipogenic progenitors. Nat Med (2015) 21:786-94. doi:10.1038/nm.3869

112. Sun L, Louie MC, Vannella KM, Wilke CA, LeVine AM, Moore BB, et al. New concepts of IL-10-induced lung fibrosis: fibrocyte recruitment and M2 activation in a CCL2/CCR2 axis. Am J Physiol Lung Cell Mol Physiol (2011) 300:L341-53. doi:10.1152/ajplung.00122.2010

113. Barbarin V, Arras M, Misson P, Delos M, McGarry B, Phan SH, et al. Characterization of the effect of interleukin-10 on silica-induced lung fibrosis in mice. Am J Respir Cell Mol Biol (2004) 31:78-85. doi:10.1165/ rcmb.2003-02990C

114. Yang L, Kwon J, Popov Y, Gajdos GB, Ordog T, Brekken RA, et al. Vascular endothelial growth factor promotes fibrosis resolution and repair in mice. Gastroenterology (2014) 146:1339-50.e1. doi:10.1053/j. gastro.2014.01.061

115. Heinrichs D, Knauel M, Offermanns C, Berres M-L, Nellen A, Leng L, et al. Macrophage migration inhibitory factor (MIF) exerts antifibrotic effects in experimental liver fibrosis via CD74. Proc Natl Acad Sci U S A (2011) 108:17444-9. doi:10.1073/pnas.1107023108

116. Bernhagen J, Krohn R, Lue H, Gregory JL, Zernecke A, Koenen RR, et al. MIF is a noncognate ligand of CXC chemokine receptors in inflammatory and atherogenic cell recruitment. Nat Med (2007) 13:587-96. doi:10.1038/ nm1567

117. Liang Y, Luo J, Lu Q, Zhou Y, Wu H, Zheng D, et al. Gene profile of chemokines on hepatic stellate cells of schistosome-infected mice and antifibrotic roles of CXCL9/10 on liver non-parenchymal cells. PLoS One (2012) 7:e42490. doi:10.1371/journal.pone. 0042490

118. Tager A, Kradin R, LaCamera P, Bercury S, Campanella G, Leary C, et al. Inhibition of pulmonary fibrosis by the chemokine IP-10/CXCL10. Am J Respir Cell Mol Biol (2004) 31:395404. doi:10.1165/rcmb.2004-0175OC

119. Poelstra K, Beljaars L, Melgert BN. Cell-specific delivery of biologicals: problems, pitfalls and possibilities of antifibrotic compounds in the liver. Drug Discov Today (2013) 18:1237-42. doi:10.1016/j.drudis.2013.05.013

120. Madsen DH, Jürgensen HJ, Ingvarsen S, Melander MC, Vainer B, Egerod KL, et al. Endocytic collagen degradation: a novel mechanism involved in protection against liver fibrosis. J Pathol (2012) 227:94-105. doi:10.1002/ path. 3981

121. Madsen DH, Leonard D, Masedunskas A, Moyer A, Jürgensen HJ, Peters DE, et al. M2-like macrophages are responsible for collagen degradation through a mannose receptor-mediated pathway. J Cell Biol (2013) 202:951-66. doi:10.1083/jcb.201301081

122. Wittrant Y, Theoleyre S, Couillaud S, Dunstan C, Heymann D, Redini F. Regulation of osteoclast protease expression by RANKL. Biochem Biophys Res Commun (2003) 310:774-8. doi:10.1016/j.bbrc.2003.09.084

123. Matsumoto M, Kogawa M, Wada S, Takayanagi H, Tsujimoto M, Katayama $\mathrm{S}$, et al. Essential role of p38 mitogen-activated protein kinase in cathepsin $\mathrm{K}$ gene expression during osteoclastogenesis through association of NFATc1 and PU.1. J Biol Chem (2004) 279:45969-79. doi:10.1074/jbc.M408795200

124. Sundaram K, Nishimura R, Senn J, Youssef R, London S, Reddy S. RANK ligand signaling modulates the matrix metalloproteinase- 9 gene expression during osteoclast differentiation. Exp Cell Res (2006) 313:168-78. doi:10.1016/j.yexcr.2006.10.001

125. Jiang D, Liang J, Hodge J, Lu B, Zhu Z, Yu S, et al. Regulation of pulmonary fibrosis by chemokine receptor CXCR3. J Clin Investig (2004) 114:291299. doi:10.1172/JCI16861

126. Guilherme RF, Xisto DG, Kunkel SL, Freire-de-Lima CG, Rocco PR, Neves JS, et al. Pulmonary antifibrotic mechanisms aspirin-triggered lipoxin A(4) synthetic analog. Am J Respir Cell Mol Biol (2013) 49:1029-37. doi:10.1165/ rcmb.2012-0462OC

127. Alagesan S, Griffin MD. Alternatively activated macrophages as therapeutic agents for kidney disease: in vivo stability is a key factor. Kidney Int (2014) 85:730-3. doi:10.1038/ki.2013.405

Conflict of Interest Statement: The authors declare that this review was written in the absence of any commercial or financial relationships that could be construed as a potential conflict of interest.

Copyright $\odot 2015$ Adhyatmika, Putri, Beljaars and Melgert. This is an open-access article distributed under the terms of the Creative Commons Attribution License (CC $B Y)$. The use, distribution or reproduction in other forums is permitted, provided the original author(s) or licensor are credited and that the original publication in this journal is cited, in accordance with accepted academic practice. No use, distribution or reproduction is permitted which does not comply with these terms. 